\title{
PSYCHE.
}

\section{A CONTRIBUTION TOWARD A KNOWLEDGE OF THE LIFE HISTORY OF CULEX SOLLICITANS. PLATE 1.}

BY JOHN B. SMITH, NEW BRUNSWICK, N. J.

The life history of a mosquito is ordinarily supposed to be rather a simple affair, and when egg, larva, pupa, and adult are known and the stage in which the winter is passed, it is assumed that little more remains to be learned. Yet of at least one species this is so little true, that our knowledge of the ordinary life cycle is a mere introduction to a real history of the species.

The species referred to is Culex sollicitans Wlk., which breeds abundantly along the shore districts in New Jersey, and which I have had under close observation during a portion of the season of 1901 , and almost the entire season of 1902 . Yet after carefully reviewing the results of the work done and the observations made, it appears that there is at least one full season's work yet required to clear up the questions left unsolved or raised by what has been already learned.

The salt-marsh mosquito is, from the economic standpoint, the most important species that occurs in New Jersey, and it is of New Jersey conditions that I intend to speak here. It dominates the entire southern half of the State and occurs in swarms where there is no chance of mosquito breeding for miles about, except in casual rain pools - and there the larva is never found. I do not mean to contradict observations made elsewhere, or to question conclusions drawn from such observations: I mean only to state actual facts and the deductions I make from them! It is quite possible that elsewhere, under other climatic conditions, these deductions may prove incorrect; but it will need equally extensive observations to demonstrate this.

The species passes the winter in the egg stage. This is demonstrated negatively by a failure to find adults at any time during the winter in quarters where the species is dominant, and where other species of Culex and ANopheles may be found. Positively it is proved by the fact that very early in spring, swarms of minute larvae appear in winter-filled pools, as soon as the temperature reaches $50^{\circ}$ Fahrenheit or over, and when not an adult can be found on the closest search.

Early in April (4) larvae pretty well grown were found in Cape May County in pools, high above ordinary or even summer storm tides, formed by the heaviest 
winter storms and already drying down. These were found after a day of search for adults in which Culex pungens and (probably) C. restuans and Anopheles punctipennis were found; but no $C$. sollicitans. The same story was repeated on the IIth; and on the I $9^{\text {th }}$ and 2 oth, as the advance of the season cut off pools and ditches from tide connection, it was quite interesting to watch the appearance of the baby larvae in pool after pool and ditch after ditch.

A pool in which on the afternoon of the 18 th there was no trace of larvae, about which not an adult could be stirred up, swarmed with minute larvae on the morning of the igth. They had hatched during the night, from eggs that were already in the water and that required only the proper temperature to bring them out. This pool had been severed from the tide not over 48 hours and the resulting uniformity of temperature was sufficient to produce the proper condition for the larval life. At this time the temperature of the sea water in a creek at half tide was $50^{\circ}$. The temperature of the pools in which the young larvae appeared was $52^{\circ}$, and the older pools in which larvae were nearly full grown were at $54^{\circ}$, all Fahrenheit.

A very suggestive condition of affairs was found in a low meadow well above tide level, which had become filled with snow and rain and by drainage and formed a shallow pond about $\mathrm{I} \frac{1}{2}$ acres in area. I know positively that this area was dry except in one low corner during the entire season of $190 \mathrm{r}$ between May ist and September ${ }^{1} 5^{\text {th, }}$, and I am informed and believe that it remained dry until late December. At all times during the summer the meadow swarmed with C. sollicitans and now, April 18, 1902, this entire area was inhabited by larvae of that species already nearly full grown; some, indeed, in the more shallow areas were already in the pupal stage. Obviously the eggs must have been laid in the dry meadow during the summer, for at no time when mosquitoes were flying was there any water to lay them into.

A large number of adults was bred from larvae gathered from pools of all kinds, ranging from fresh to very salt water and, except in one instance, only $C$. sollicitans was bred. The exception was a single lot of larvae from a pool of brackish water from which $C$. cantans was also obtained.

The larva of C. sollicitans is light slate gray in color, the head yellow, without markings of any kind, anal siphon short and stout, antenna short, slender, black at the tip, without obvious set off or prominent tufting. The figure (pl. I, fig. I) shows very fairly the appearance of the larva; the shape of the head and especially of the vertex being quite characteristic. Several other larvae resemble this and are not readily separable - notably those of $C$. cantans and C. taeniorhynchus.

What happened in Cape May County between April 20 th and June I5th, when next I went there, I am unable to say; but the season had been very dry, 
pools were everywhere much reduced, swarming with larvae and pupae, while the grass was filled with males. There were very few females and evidently, of the new brood just coming to maturity, only the males had yet emerged. A month later only a few bodies of water remained and they were drying up fast - so fast indeed, that thousands of larvae failed to come to maturity, and the half or quarter inch of water remaining in some pools was one squirming, wriggling mass.

A systematic search was now made for the eggs and they were found in quantity after the right places were determined. Of the older females, flying July 8-20, almost all contained eggs, ranging from soft, white, through pearly, translucent, as the shell formed, to black. Black eggs only were found in the meadows, well above the recent water line of such pools as yet remained, in the black mud in which their color made them almost invisible. It has been recently suggested that black is an unusual or exceptional color for mosquito eggs and that the habit of ovipositing on land rather than water is exceptional. This may be true for Louisiana where the observations leading to that suggestion were made; but in New Jersey C. sollicitans certainly lays black eggs in black mud. No other color would do so well under the circumstances and,. outside the body of the mosquito, I never saw C. sollicitans eggs other than black! From a piece of sod about 4 inches square I washed the surface mud into a basin of water, waited until the whole settled to the bottom, to make certain that the eggs did not float, and next morning I had over 300 and possibly 500 lively young wrigglers.

It is important to note, in this connection, that though Mr. E. L. Dickerson (my assistant) and I collected several hundreds of specimens of mosquitoes between July 8th and 2 oth no examples of $C$. taeniorhynchus were seen, nor had I at any time previously in 1902 collected $C$. taeniorhynchus near this point. Neither was that species bred out of any larvae taken from the pools where we were then experimenting.

Two large sods were cut out of the marsh, well above any recent pools, and these were carried to New Brunswick to serve for laboratory tests. One sod was kept entirely dry, the other was kept constantly moist though never covered with water. The presence of eggs in both sods was demonstrated by actual examination and, at intervals, small pieces of sod were covered with water and the results were noted. From the dry sod larvae were always obtained in a short time - from one half to one hour; from the wet sod no larvae were obtained and all the eggs found were burst.

Two lots of larvae from the dry sod were bred to maturity and all the adults proved $C$. taeniorhynchus! The larvae were those of $C$. sollicitans except that they seemed undersized; but the adults were unquestionably the other species. Finally, September $2 \mathrm{I}$, two months after I took it up, I placed the remnants of the moist sod 
in a large dish of water and next morning, to my great surprise, I found a fair lot of larvae. Out of these I obtained 8 adults and of these three were undoubted $C$. sollicitans! It is a fair suggestion that there is something yet to be learned concerning the relationship between $C$. sollicitans and C. taeniorhynchus.

The season at the point where the collections were made was phenomenally dry and all pools and ditches remained dry until September 5 or 6 , when a heavy storm filled everything. On the inth, Mr. Dickerson investigated, found every pool swarming with recent larvae, and brought up 20 small sods from ten separate places well above the pool line and which had been entirely dry since early July and probably a month before that date. All but two of these sods had been tested and had shown the presence of eggs, hence it was a fair conclusion that eggs were generally distributed all over the meadow. From eight of these sods larvae were bred in the laboratory.

The eggs are spindle shaped just a little curved, shining, and when the larva hatches the upper $\frac{1}{4}$ lifts off as if by a hinge.

Another observation made at Beach Haven early in August throws further light upon the egg-laying habits of the species. A very heavy rain after a long dry spell, followed by a series of showers during which 3 or 4 inches of rain fell, filled every low area in the meadows with from $\frac{1}{2}$ to $\mathrm{r} \frac{1}{2}$ inches of water. Within twenty-four hours this entire area was swarming with larvae just hatched and in forty-eight hours millions had perished because the water had disappeared: evaporated by the hot sun or soaked into the parched soil. It would be easy to add to this further observations, all tending to the point that the female oviposits almost anywhere in the meadows, at the base of grasses; but it would seem as if the above were sufficient.

I stated that, in early July, there was no trouble in finding gravid females and, indeed, almost all the females taken were full of eggs. It is a curious fact that this condition was not again duplicated later in the season.

From the beginning of September to the middle of October collections were made daily on the Newark meadows, and from that time to the end of mosquito flight in November, collections were made at least once and usually twice a week. Yet of the many hundreds of examples dissected not one contained mature eggs. After a long period of drought which left the upper part of the Newark meadows dry, C. sollicitans became very scarce in early September. On the night of the $4^{\text {th }}$ and $5^{\text {th }}$ there was a very heavy tide that flooded the meadows to the edge of the City, and covered the marsh tract at the mouth of the Elizabeth River. On the 6th Mr. H. H. Brehme, who made the meadows investigations for me, found everything swarming with recently developed larvae which grew rapidly as the pools gradually dried up. By the $\mathrm{r} 6$ th almost the entire brood was mature and 
the pools were crowded with pupae and a small proportion of full grown larvae. The grass was now full of adults which made life almost unbearable unless some method was used to keep them off. The practical disappearance of the earlier broods before the new brood issued fixed the age of these specimens and there was no other general brood that developed later on these meadows. I thought this a good opportunity to ascertain how long a time it would require for eggs to develop and hence had the collections made daily for some time. Yet at the end of the season I had no evidence that even one example out of the entire brood laid even a single egg! Lot after lot was received with absolutely undeveloped ovaries and not even a single example was found having eggs ready to be laid! The question is, did they lay any at all? In sods collected after the water had drained off none were found, and practically I do not know where the eggs are that will start $C$. sollicitans next spring. Dr. Dyar has suggested, in connection with another species, that of eggs laid in spring some might hatch during the summer but that others would lie over until the season following. It is, of course, possible that the same thing occurs in this case and that unhatched eggs are yet on the meadows, ready to develop under favorable conditions next spring. As to the number of eggs laid by a female, the dissections made gave an average of about 175. A very few reached 200 and very few had less than $5^{\circ}$ unless the number was very small.

Another peculiarity of $C$. sollicitans in New Jersey is, its habit of travelling long distances inland, either by flight or by allowing itself to be carried by the prevailing winds. After the middle of July the entire pine region of South Jersey gradually fills up with these insects, sometimes swarming miles from any water and forty miles from any point where $C$. sollicitans larva has ever been found. On two occasions I made systematic search during two or three days, over a large area where $C$. sollicitans was the dominant species, finding larvae of forms whose adults escaped attention, but none of the shore species. Nor did I ever find in the pines even one adult example in which the ovaries were at all developed. August

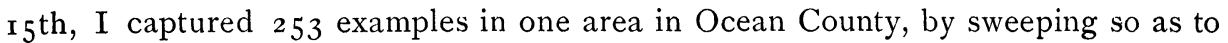
get old, inactive specimens, and not one of these had the ovaries in the least developed. A lot of 90 was captured a few days before by picking them from the coat of the collector and these were found in a similar undeveloped condition. I omitted to mention that in these flights, so far away from home, the males have no part - only the females wander. It is quite certain that none of the millions of these mosquitoes that infest the Jersey pines ever reproduce, because the surroundings are not suitable; and it is almost equally certain that they could not if they had the opportunity, because the ova simply do not develop.

The life period of the individual of this species is not determined; but it is 
probably of considerable length, especially in those forms that do not reproduce. That they may bite more than once is certain, and direct experiment has proven that a full meal of blood may be so completely digested in one week, that scarcely a trace remains. The examination of a large number of specimens seems to indicate that blood food stimulates ovarian development, for in the great majority of cases where I found fully developed ova I found also blood remnants. In those cases in which such remnants were not found it cannot be safely concluded that such food had not been taken more than a week previously. But I did find numerous instances of ova starting development where the alimentary canal contained only a colorless liquid; probably plant juices.

Larvae of $C$. sollicitans were not found after November 4, but adults continued until well along in that month. In shelters along the Newark meadows where $C$. nigritulus, another salt water species, was found hibernating, not a C. sollicitans occurred in December.

Altogether the life cycle of this species offers points of interest that will require at least another full year to work out.

\section{Plate i.}

Culex sollicitans Wlk.

I. Full-grown larva.

2. Pupa.

3. Adult male, from above.

4. Adult female, from side.

5. Head of larva from beneath. 
Psyche, Vol. 10.

Plate I.

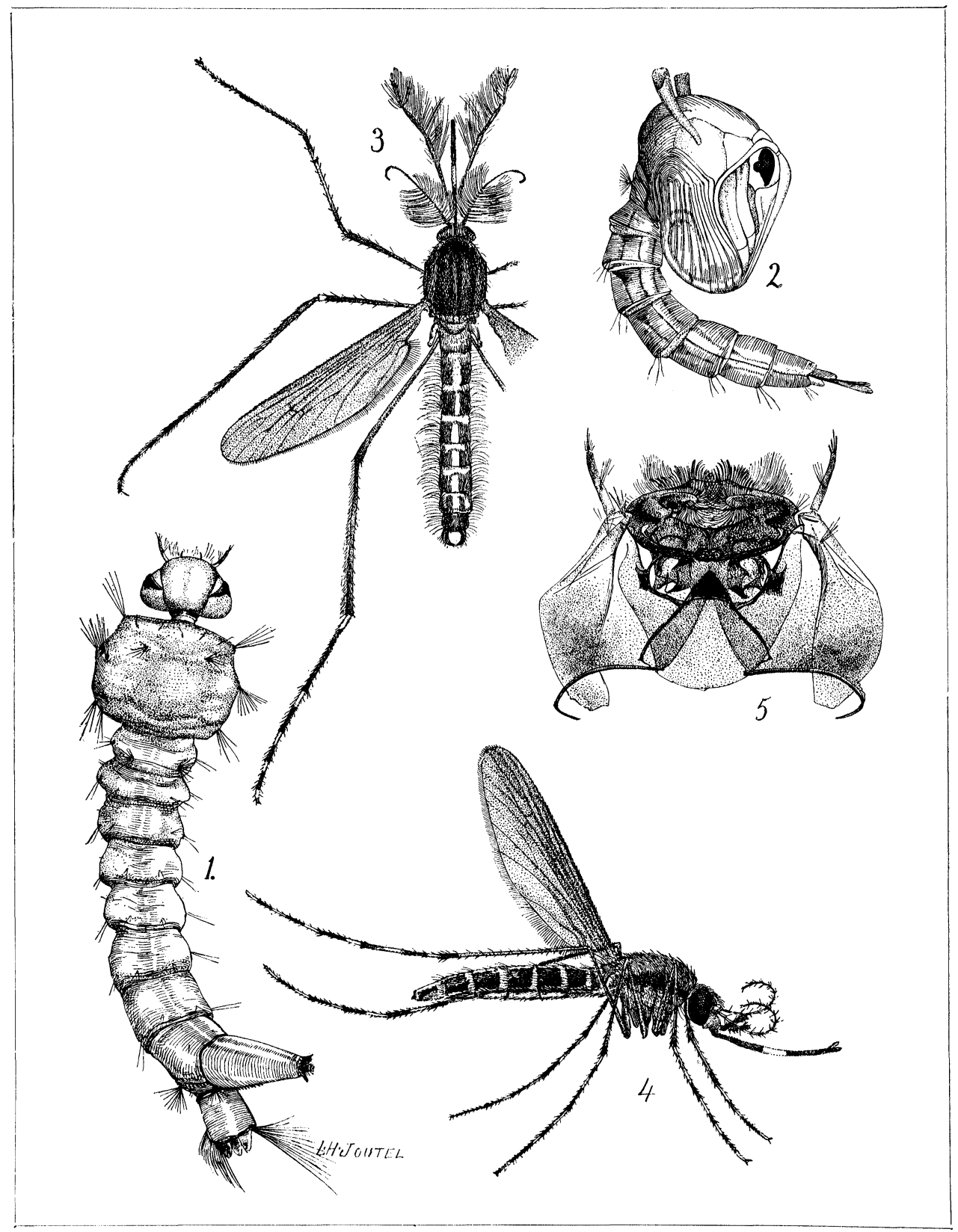

SMITH :-CULEX SOLLICITANS WLK. 

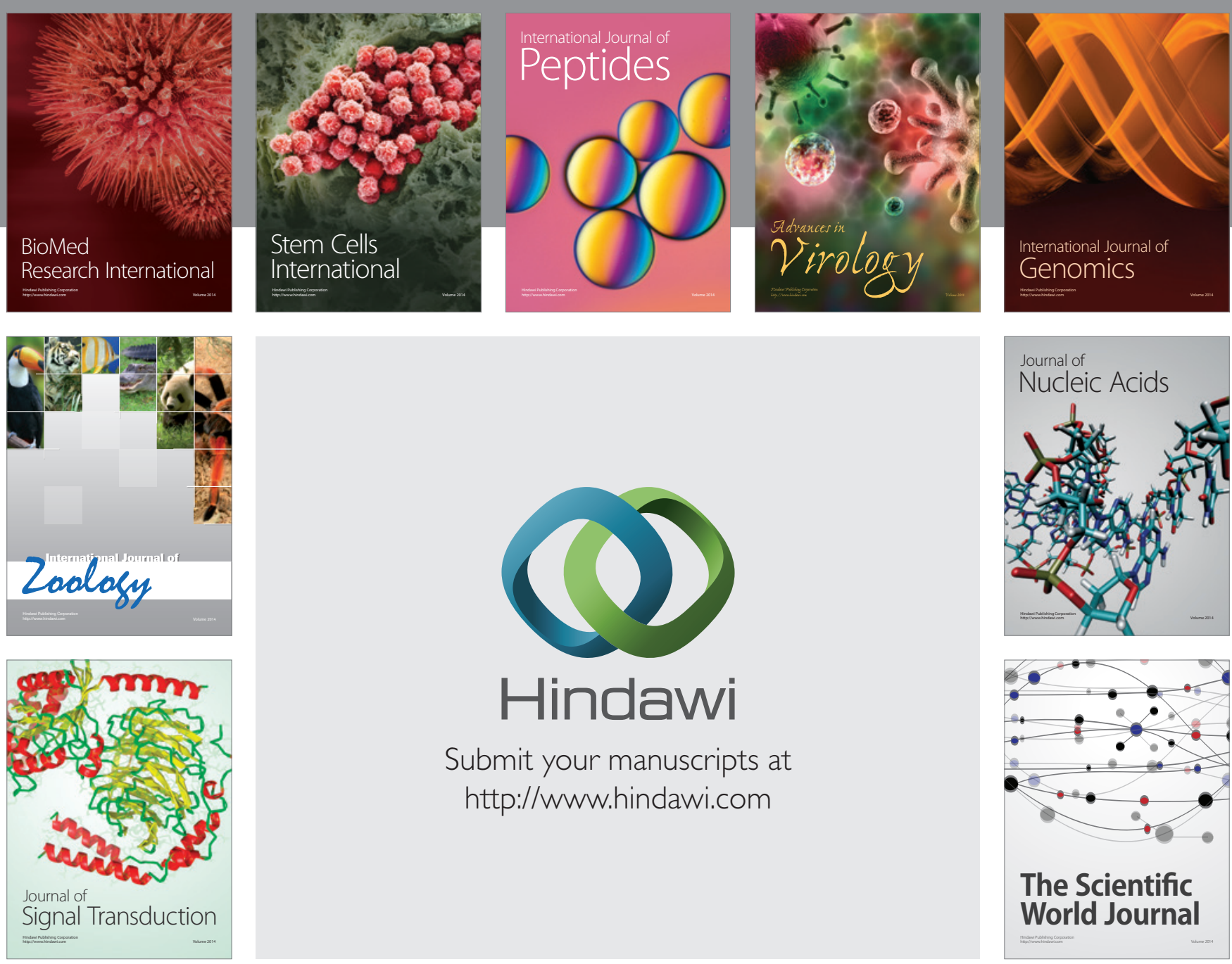

Submit your manuscripts at

http://www.hindawi.com
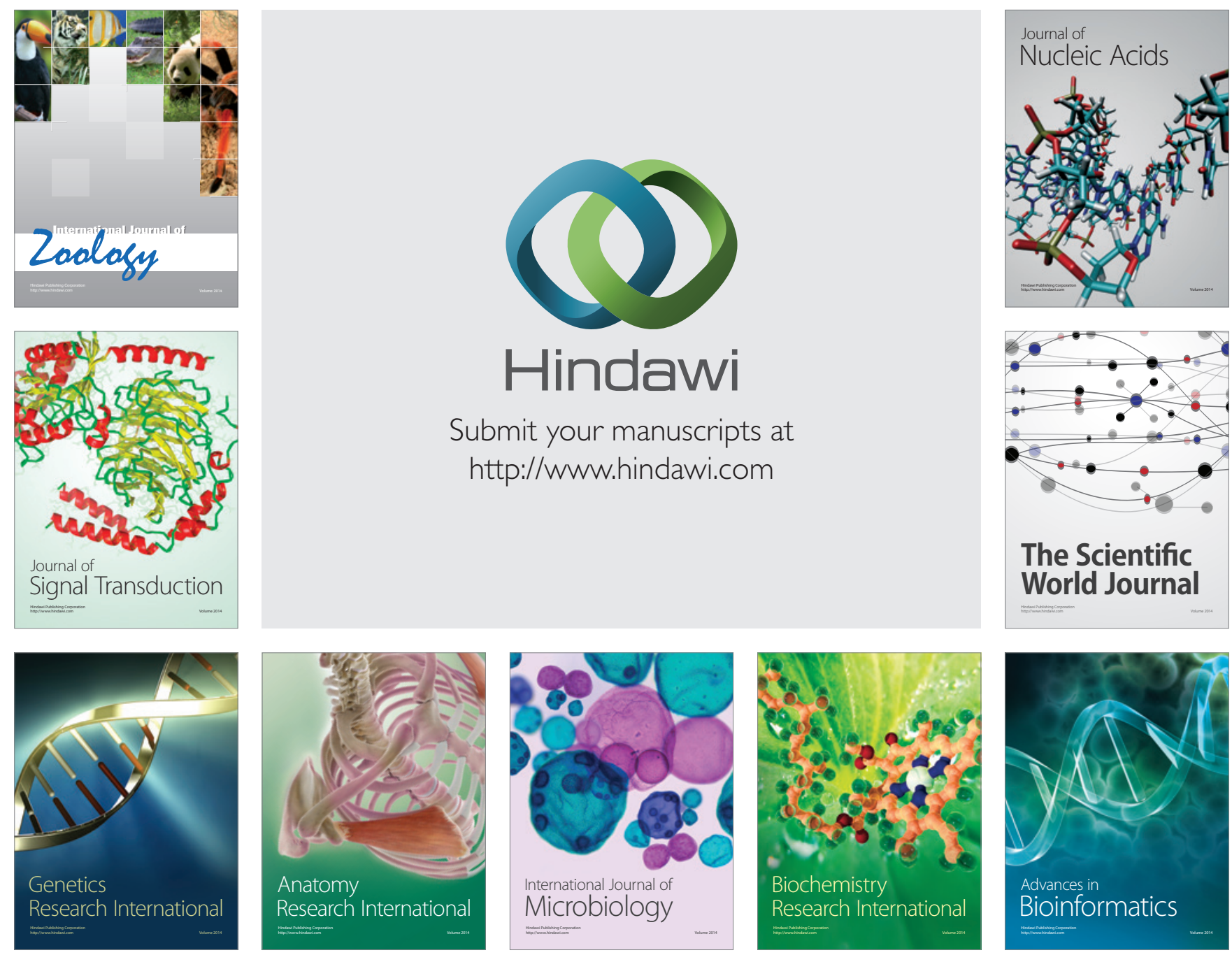

The Scientific World Journal
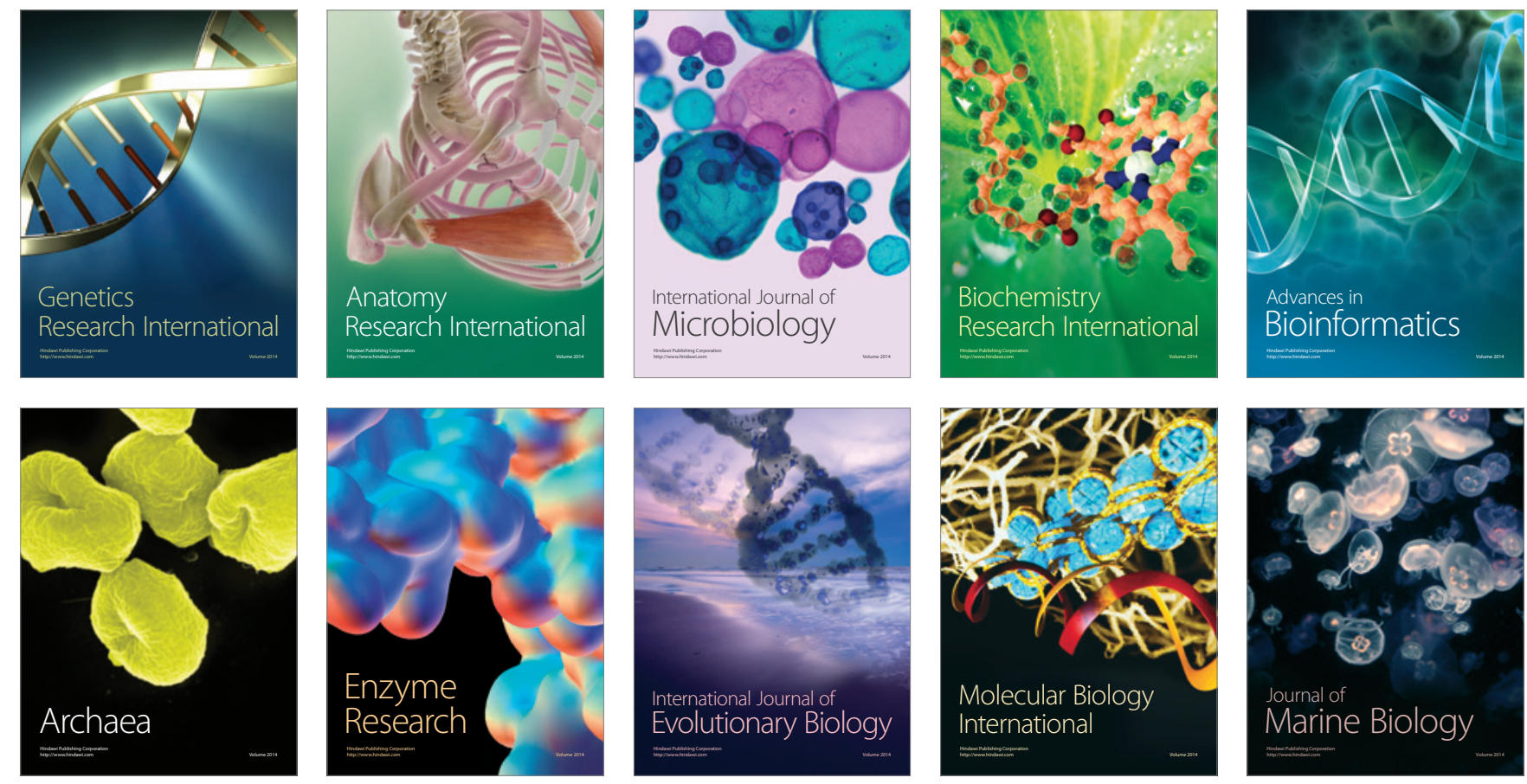